\title{
Estabilidade na mudança: famílias de partidos e a hipótese do congelamento do sistema partidário no Brasil (1982-2018)'
}

Fernando Guarnieri ${ }^{2}$

\section{Resumo}

Neste artigo, pretendo estudar a dinâmica do sistema partidário brasileiro a partir da hipótese do “congelamento" do sistema partidário de Lipset e Rokkan (1967). Quando agrupamos os partidos em famílias, vemos que, entre os anos 1990 até o fim da primeira década do século XXI, o sistema partidário brasileiro parece tão "congelado" quanto o europeu. Após 2010, assim como na Europa, pequenos partidos de direita ganham força, mas o apoio das grandes famílias "esquerda" e "direita” permanece relativamente constante. Também constato alguma estabilidade quando agrupamos os partidos conforme sua genealogia. Essa dinâmica é similar àquela dos sistemas partidários europeus. A contribuição do artigo está em ser o primeiro a testar explicitamente a aplicação da hipótese do congelamento do sistema partidário de Lipset e Rokkan para o caso brasileiro, assim como o primeiro a sugerir a construção de famílias partidárias de modo sistemático utilizando as sugestões de Mair e Mudde (1998).

Palavras-chave: Sistema Partidário. Volatilidade. Família de partidos.

\section{A hipótese do congelamento dos sistemas partidários}

Ao explicar a origem do sistema partidário europeu, Lipset e Rokkan (1967) descrevem como, entre meados do século XIX e começos do século XX, uma série de clivagens sociais se organizou em partidos. Essas

\footnotetext{
I Os dados e o script para a replicação das figuras e tabelas utilizados neste artigo podem ser solicitados para fhguarnieri@iesp.uerj.br

2 Professor adjunto do Instituto de Estudos Sociais e Políticos (IESP) da Universidade do Estado do Rio de Janeiro (UERJ). Doutor em ciência política pela Universidade de São Paulo (USP). E-mail: fhguarnieri@iesp.uerj.br
}

\section{(c)) Er}

Direito autoral e licença de uso: Este artigo está licenciado sob uma Licença Creative Commons. Com essa licença você pode compartilhar, adaptar, para qualquer fim, desde que atribua a autoria da obra, forneça um link para a licença, e indicar se foram feitas alterações. 
clivagens se deram em torno, principalmente, das duas grandes revoluções: a revolução nacionalista e a revolução industrial. Da construção dos estados nacionais, que, na Europa, somente teve seu fim em meados do século XIX, surgiram as clivagens Centro vs Periferia, opondo as forças centralizadoras aos antigos potentados locais e a clivagem Estado vs Igreja, opondo os proponentes e os opositores ao Estado laico. Destas clivagens, teriam nascido os partidos liberais, regionais, conservadores e religiosos. $\mathrm{Na}$ revolução industrial, houve conflitos em torno de interesses materiais, como a oposiçáo entre as elites urbanas e rurais refletida na clivagem Rural vs Urbano e a clivagem Trabalhadores vs Burguesia. Destas clivagens, teriam nascido os partidos agrários, camponeses, trabalhistas, socialistas e sociais-democratas (CARAMANI, 2004).

Essa dinâmica em que clivagens sociais se partidarizam deveria renovar o sistema partidário constantemente conforme novos conflitos surgem. Isso até certo ponto ocorre, como demonstra a aparição dos partidos comunistas após a revolução russa, e dos partidos verdes e congêneres no período pós-industrial. No entanto, conforme observado por Lipset e Rokkan (1967, p. 50): "[...] the party systems of the 1960's reflect, with few but significant exception, the cleavage structures of the 1920'”. Essa proposição ficou conhecida como a hipótese do "sistema partidário congelado".

Outros pesquisadores confirmaram esses achados (ROSE; URWIN, 1970) e se tornou um consenso que, até os anos 1960, o sistema partidário de fato refletia as estruturas de clivagens dos anos 1920. No entanto, vários autores questionaram a continuidade do congelamento em épocas posteriores.

Maguire (1983) replica o trabalho de Rose e Urwin para além dos anos 1960 e seus dados questionam a ideia de um sistema estável. Pedersen (1983) mostrou como, neste período, a volatilidade agregada era alta; mas, seus dados cobriam apenas o período entre 1960 e 1980 náo podendo ser comparado com o período entre 1920 e 1960. Dalton, Flanagan e Beck, utilizando survey, chega à conclusão de que "[...] the structure of democratic party systems, frozen for so much of our lifetimes, is beginning to thaw" (DALTON; FLANAGAN; BECK, 1984, p. 457); mas, seu trabalho também cobre um período limitado. 
Apesar dessas várias opiniōes em contrário, Peter Mair (1993, p. 127), explorando as deficiências apontadas acima, afirmava em 1983 que: "[...] electorates in Europe in the 1980s have in general proved as stable and as predictable as they were at the period in which Rokkan referred to the freezing hypothesis. At least up to now, the general pattern shows more rather than less stability".

Mat Golder (2003, p. 8), dez anos depois de Mair, comenta que, apesar de novos partidos serem comuns na Europa,

[...] only $7.8 \%$ of new parties have ever managed to enter government and less than $1 \%$ have ever been a formateur... [o]f those parties that have actually entered government, half have since disappeared. This means that parties established prior to 1930 have been surprisingly successful at keeping the door to government participation shut to new parties.

Estes últimos trabalhos mostram que, quando se avaliam períodos mais amplos, a hipótese do congelamento se sustenta. O problema do escopo temporal é que, ao se concentrar apenas nos períodos após os anos 1960 , como acontece com os surveys, perde-se uma perspectiva comparada. Quando sáo comparados períodos maiores de tempo, vemos que não houve muitas mudanças. Utilizando uma base de dados que cobria o período entre os anos 1920 e 1990, Mair (1997) mostra que sempre houve volatilidade nos sistemas partidários europeus, mas a volatilidade agregada média seria baixa (9\%) tanto no período anterior aos anos 1960 quanto no período posterior.

Outro problema é que a maior parte dos críticos focou mais na estabilidade de partidos individuais do que na permanência das clivagens. O problema de se focar em partidos individuais é de que a proposição de Lipset e Rokkan fala da estabilidade das clivagens e não se deve tomar como automático o reflexo de certas clivagens em determinados partidos. As clivagens são representadas por famílias de partidos e não por partidos individuais. Voltarei a esta importante distinção mais à frente.

Apesar da proposição de Lipset e Rokkan ser colocada como uma hipótese, estes autores, na verdade, não desenvolvem uma teoria para o congelamento do sistema partidário. Mais recentemente, outros autores tentaram desenvolver esta teoria. Mair (1993, 1997) defende que a 
resiliência dos novos partidos se daria menos pela permanência das divisóes sociais e mais pela capacidade de as organizaçóes partidárias se adaptarem aos novos tempos. Caramani (2008) explica a persistência da estrutura de clivagens pela supremacia da clivagem esquerda-direita com o predomínio dos partidos conservadores, liberais e sociais-democratas. Esse predomínio seria algo comum a todos os países europeus.

Do ponto de vista empírico, a questão do congelamento do sistema partidário recebeu variado tratamento. Os críticos da ideia de estabilidade do sistema partidário recorriam a três fontes de evidências: os padróes de volatilidade agregada utilizando o índice desenvolvido por Pedersen (1979); o "sucesso" de novos partidos à esquerda e à direita (KITSCHELT, 1997); e o declínio das organizaçōes partidárias (LAWSON; MERKL, 1988).

Pedersen $(1979,1983)$ procura verificar a estabilidade do sistema partidário europeu como proposta por Lipset e Rokkan (1967) e, para isso, cria um índice de volatilidade que se tornou o padrão na literatura. Esse índice consiste na soma de ganhos ou perdas dos partidos entre dois períodos de tempo dividido por dois. Agregam-se ganhos ou perdas individuais sem levar em consideração a direção deste ganho ou perda. Por meio deste índice, Pedersen (1979, p. 1) afirma que:

During the 1960s it was a widely held view among political scientists that European party systems were inherently stable structures which - with a few exceptions - reflected the societal cleavage structures of the past (Lipset and Rokkan, 1967: 50). This view was even bolstered with strong empirical evidence pertaining to the party system at the level of the electorate.

[...]

These are developments which are by now clearly visible. They seem to indicate that even if party systems may still reflect the traditional cleavage structure in the society, the significant exceptions that Rokkan and Lipset were talking about are no longer few, but constitute a larger and growing part of all European party systems.

Mainwaring e Zoco (2007) discutem a questão da estabilidade do sistema partidário ao examinarem 47 democracias. Eles defendem que um sistema partidário estável reforça uma efetiva representação programática. Em sistemas instáveis, é difícil para o eleitor saber quais são os partidos e o que eles defendem; e isso acaba enfraquecendo a capacidade das siglas 
partidárias funcionarem como atalhos informacionais para uma decisão em bases programáticas. Para medir a estabilidade do sistema partidário, os autores utilizam o índice de volatilidade de Pedersen. Sua conclusão é que sistemas partidários com maior duração são mais estáveis que sistemas mais recentes.

Já em trabalho mais recente Maiwaring, Gervasoni e España-Najera (2016), seguindo Powell e Tucker (2014) e outros estudos, principalmente os que se dedicavam às democracias pós-comunistas, diferenciam entre volatilidade no interior do sistema e volatilidade extrassistema, isto é, entre a troca de votos entre partidos que já se encontravam no sistema partidário e entre estes e novos partidos. A entrada de novos partidos daria uma ideia melhor da transformação dos sistemas partidários. Para verificar estas volatilidades eles constroem uma base de dados cobrindo 67 países e um recorte temporal com dados desde 1945 ou da data em que o regime se tornou de fato competitivo. Sua conclusão é que novos entrantes tiveram menos sucesso em democracias há mais tempo estabelecidas, o que seria consistente com a noção de sistema partidário congelado de Lipset e Rokkan (1967). Já democracias mais jovens teriam, na média, sistemas partidários instáveis.

Embora a diferenciação entre volatilidade interna e externa permita aferir de algum modo a estabilidade do sistema partidário, há um problema de agregação na análise de Pedersen (1979, 1983) e Maiwaring, Gervasoni e España-Najera (2016). A unidade de análise destes autores é o partido individual. Os autores procuram tirar conclusóes sistêmicas a partir da soma de comportamentos individuais. Mas, como lembra Peter Mair (1997, p. 65):

Putting these points together suggests an important distinction between the individual party organization, on the one hand, and the organized expression of the cleavage, on the other, in that the latter is capable of incorporating more than one party. In other words, there is no simple one-to-one correspondence between an individual party organization and the presence of a cleavage, for while the political relevance of the latter requires expression in some form of political organization, such a political organization may nevertheless include two or more parties competing for more or less the same constituency. Thus while individual parties may rise and fall, the major 'alternatives' may therefore persist. In France, for example, despite 'marked organizational fragmentation both at the level of interest articulation 
and at the level of the parties [...] no analyst of French politics is in much doubt about the underlying continuities of sentiment and identification on the right no less than on the left of the political spectrum:

Para Mair (1997), índices como o de Pedersen não permitem distinguir mudanças entre aliados em certas clivagens e mudanças entre adversários. Uma troca de votos entre socialistas e comunistas, por exemplo, seria equivalente a uma troca de votos entre esses partidos e um partido de direita. As duas situaçóes indicariam instabilidade; mas, apenas a segunda refletiria instabilidade de clivagens, ou uma real mudança no sistema partidário. Enquanto a medida de volatilidade partidária nos dá o grau de incerteza sobre quais partidos farão parte do governo a volatilidade entre famílias nos indica o grau de incerteza quanto ao tipo de política que será implementada pelo governo.

Portanto, além da distinção entre volatilidade intra e extrassistema, é necessário distinguir a direção desta volatilidade. E esta seria captada pela distinção entre a volatilidade partidária e volatilidade entre famílias de partidos. Rokkan (1970) já defendia que a estabilidade do sistema partidário europeu poderia ser constatada pela limitada variação de tipos de partidos que surgiram com a massificação da política.

A dificuldade em se medir a volatilidade entre famílias de partidos está justamente na definição do que seriam estas famílias. A classificação de partidos em famílias é essencial para se comparar sistemas partidários tanto entre países quanto no tempo (ELFF e POSTBOX, 2013; FREIRE; TSATSANIS, 2015) ${ }^{3}$. Essa abordagem remonta ao estudo clássico de Rokkan (1970), que, como vimos, baseou sua categorização de partidos em quatro "clivagens críticas": sujeito vs cultura dominante; igrejas vs governo; economia primária vs secundária; e trabalhadores vs empregadores ou proprietários. Com base nestas clivagens, von Beyme (1985) e Seiler (1980) vão propor algumas famílias. O primeiro autor vai identificar como famílias ou "grupos ideológicos": liberais, conservadores, partidos operários,

3 É importante diferenciar a classificação de partidos em famílias da tipologia dos partidos. Enquanto a primeira diz respeito ao sistema partidário e sua relação com clivagens sociais, políticas, religiosas etc. As tipologias dizem respeito ao partido individual e sua organização. Sobre tipologia de partidos ver: Gunther e Diamond (2003), Krouwel (2006) e Wolinetz (2002). 
partidos agrários, partidos regionais, partidos cristãos, partidos comunistas, partidos fascistas, partidos de protesto e movimentos ecológicos; já Seiler (1980) identifica oito "famílias políticas": partidos burgueses, partidos operários, partidos centralistas, partidos populistas, democratas cristáos, partidos anticlericais, partidos agrários e partidos comunistas.

O artigo de Mair e Mudde (1998) é o primeiro estudo sistemático que procura identificar os fatores que caracterizariam uma família de partidos. Os autores identificam quatro abordagens na literatura que propóem critérios para a classificação destas famílias: aquelas que identificam as famílias pela origem dos partidos, aquelas que focam na filiação institucional a associações internacionais, aquelas que procuram similaridades nas políticas propostas ou na ideologia e, por fim, aquelas que olham apenas para o nome ou a sigla do partido. Após criticar essas abordagens, os autores sugerem que as famílias sejam identificadas apenas por sua origem e por sua ideologia. No primeiro caso, interessa como os partidos surgem, quais movimentos estão em sua base e quais clivagens refletem. No segundo caso. sugerem aferir a ideologia a partir da análise do conteúdo dos programas partidários.

Ao se classificar os partidos em famílias, é possível investigar a volatilidade no interior delas. Em estudo recente de König, Marbach e Osnabrügge (2013), por exemplo, utilizam os programas de partidos de 25 países em um período entre 1945 e 2010 para identificar sua posição na escala esquerda-direita e classificá-los em famílias. Os autores mostram que desta perspectiva o sistema partidário europeu havia realmente se congelado mesmo após o texto de Lipset e Rokkan (1967). A distribuição da posição ideológica de cada família no tempo é praticamente constante e, apesar da entrada de novos partidos, os partidos mais antigos estão presentes e com força em quase todo o período. Conforme König, Marbach e Osnabrügge (2013, p. 468), "[... ] compared to the puzzling volatility of existing estimates, we find that parties more modestly change their left-right positions over time". 


\section{Famílias de partidos e a estabilização do sistema partidário no Brasil}

A discussão sobre o congelamento do sistema partidário ficou praticamente limitada à Europa Ocidental. Em uma das poucas tentativas de se estender a análise para outros países, Mair analisa os casos do leste europeu pós-comunismo. Mair escreve pouco tempo depois da transição para um sistema eleitoral competitivo e questiona se realmente já se podia falar em sistema partidário em democracias tão recentes ecoando análises como a de Maiwaring (1999) sobre as democracias da terceira onda. A conclusão de Mair (1997) é que esses sistemas apresentam muito mais um padrão de instabilidade.

No Brasil, a discussão assume contornos semelhantes ao colocado por Mair com relação aos países pós-comunistas. Nossa democracia seria muito jovem para que pudéssemos falar em sistema partidário, isto é, em um padrão de interaçáo previsível entre partidos. A volatilidade eleitoral seria a medida por excelência desta instabilidade.

Nos anos 1990 vários autores argumentaram que arranjos institucionais, como o adotado pelo Brasil a partir da Constituição de 1988 - que combinou presidencialismo, federalismo e representação proporcional de lista aberta -, gerariam incentivos a um comportamento individualista por parte dos políticos, a partidos fracamente enraizados e a sistemas partidários instáveis. Isso levaria a crises de governabilidade e à instabilidade democrática (MAINWARING, 1991,1999; LAMOUNIER, 1992, 1994).

A comprovação empírica deste diagnóstico estava na volatilidade eleitoral. Paulo Peres (2002, p. 5), analisando os trabalhos que aplicaram o índice de Pedersen às eleiçóes brasileiras, conclui que, destes trabalhos, “[...] podemos extrair conclusóes opostas quanto à funcionalidade do sistema representativo brasileiro, passando pela constatação de sua efetividade crescente até a afirmação de sua total debilidade". Essa constatação se deve a problemas nos critérios analíticos e metodológicos daqueles trabalhos. Para superá-los, o autor busca ampliar os casos analisados, olhando para os estados, e utiliza, além da volatilidade partidária, a volatilidade ideológica, conforme proposta por Bartolini e Mair (1990). 
A conclusão de Peres (2002, p. 24) é a de que:

A volatilidade eleitoral partidária vem caindo sistematicamente desde 1986-1990, chegando a ser cerca da metade do que era naquele período. Além de apresentar uma curva descendente, o resultado da última sequência eleitoral, que é de 15,5 pontos, significa uma estabilização importante. No que se refere à volatilidade eleitoral ideológica, o índice também apresentou uma queda acentuada desde 1986-1990 até a última eleição, em 1998, chegando a apresentar uma volatilidade ideológica de apenas 1,7; menor do que a média de países europeus com democracias bem mais antigas.

Braga (2010) chega às mesmas conclusóes de Peres (2002): a volatilidade partidária estava em queda. Comparando a taxa de volatilidade brasileira com a de 38 outras democracias, dentre elas as da Europa Ocidental, a autora mostra que somente nove delas tinham índices mais baixos que o do Brasil. A autora constata a mesma queda para volatilidade ideológica (BRAGA, 2010, p. 55).

Em trabalho de 2011, Peres, Ricci e Rennó procuram entender os determinantes da volatilidade eleitoral no Brasil; após criticarem a "falácia ecológica” de análises mais agregadas, esses autores analisam a evolução da volatilidade nos estados da federação chegando a conclusóes semelhantes à de Braga (2010) e Peres (2002): a volatilidade nos estados, apesar de bem heterogênea, apresentava quase sempre uma tendência à queda o que se refletia na queda da média da volatilidade nacional.

Todos estes trabalhos estavam mais preocupados com a institucionalização do sistema partidário brasileiro do que em testar a hipótese do congelamento deste sistema. Não faria muito sentido testar o congelamento de um sistema que não fosse institucionalizado. Essa questão, da institucionalização ou não do sistema, ainda se encontra em aberto, no entanto a estabilização da volatilidade eleitoral em níveis relativamente baixos, apontada pelos trabalhos acima, nos permite perguntar se, no caso brasileiro, as clivagens que deram origem ao atual sistema partidário ainda estruturam esse sistema.

Para testar a hipótese do congelamento, é necessário identificar famílias de partidos no Brasil ${ }^{4}$. Como sugerido por Mair e Mudde (1998),

4 Os poucos trabalhos que encontrei na literatura nacional sobre partidos que tratam explicitamente de famílias de partido são os de Bolognesi (2014) e Codato, Bolognesi e Roeder (2015), que comparam partidos de direita 
podemos fazer isso de dois modos: observando a origem dos partidos e observando sua ideologia. A proposta de Peres (2002), seguida por Braga (2010), de medir a volatilidade ideológica no Brasil se aproxima de um teste da "hipótese" de Lipset e Rokkan (1967), embora não tenha sido elaborada com esse intuito precípuo. A divisão entre esquerda e direita permite identificar semelhanças entre os partidos, certa familiaridade.

No Brasil, seguindo Singer (2002), a maioria dos eleitores brasileiros, mesmo os de baixa escolaridade, se divide em esquerda, centro e direita e tende a votar de acordo com a sua preferência ideológica. Portanto, utilizando a classificação ideológica, seria possível identificar três grandes famílias.

A classificação dos partidos em famílias ideológicas não é trivial e sem controvérsias. Conforme Mair e Mudde (1998) a análise da ideologia requer uma abordagem mais abrangente e aprofundada do que normalmente se aplica à análise de posiçóes políticas, e requer a avaliação de uma variedade mais ampla de fontes documentais). Tarouco e Madeira (2013) foram uns dos poucos autores que empreenderam tal análise. Esses autores utilizam a categorização do Manifesto Research Group (MRG) que tem como base teórica a teoria da saliência, segundo a qual os partidos competem enfatizando em seus programas temas diferentes onde eles têm reconhecida competência (TAROUCO; MADEIRA, 2013, p. 153).

Utilizando categorias do MRG, classificam os programas partidários de sete partidos brasileiros - aqueles que obtiveram cadeiras em todas as legislaturas desde 1982 mais o Democratas (DEM)/Partido da Frente Liberal (PFL) e o Partido da Social Democracia Brasileira (PSDB) - e os posicionaram em uma escala esquerda-direita pela diferença entre a proporção de texto nos programas dedicada a categorias de direita e a proporção dedicada a categorias de esquerda. Embora essa classificação seja a mais adequada conforme a sugestão de Mair e Mudde, infelizmente ela gerou resultados muito diversos de outras classificaçóes ideológicas, posicionando quase todos os partidos analisados à esquerda, o que impede seu uso no presente artigo.

no Cone Sul e no Brasil, respectivamente. Estes autores se referem ao trabalho de Ennser (2012) que, por sua vez, retrabalha as sugestões de Mair e Mudde (1998) 
Outra iniciativa para classificar os partidos em famílias ideológicas foi levada a cabo por Power e Zucco Jr. (2009, 2012). Estes autores realizaram surveys com parlamentares brasileiros onde, entre outras coisas, aferem a percepção destes sobre o posicionamento ideológico de uma série de partidos e constroem uma "cartografia ideológica do sistema partidário brasileiro” (POWER; ZUCCO JR., 2009, p. 219). Os autores realizaram sete ondas de surveys que correspondem às sete legislaturas desde a redemocratizaçáo. Foram entrevistados um total de 1.146 deputados federais que posicionaram os partidos em uma escala entre 1 (esquerda) e 10 (direita). A conclusão a que os autores chegam é de que "[...] although individual Brazilian parties have clearly undergone ideological change since the late 1980s, the main legislative parties can be arrayed clearly on a classic left-right scale and that the overall ordering has been relatively stable across time" (POWER; ZUCCO JR., 2009, p. 219).

A Tabela 1 mostra a classificação dos partidos em cada ano, conforme posiçóes identificadas no survey de Power e Zucco Jr. (2011). Para classificar os partidos em famílias conforme sua ideologia, agrupei à esquerda os partidos com score menor que 4 e à direita partidos com score maior que 6. Os partidos de centro são aqueles com score entre 4 e 6 . 
Tabela I - Scores de Classificação Ideológica dos Partidos por Ano

\begin{tabular}{|c|c|c|c|c|c|c|c|}
\hline \multirow[b]{2}{*}{ Partido } & \multicolumn{7}{|c|}{ Ano } \\
\hline & 1990 & 1993 & 1997 & 2001 & 2005 & 2009 & 2013 \\
\hline PCdoB & 1,22 & 1,49 & 1,61 & 1,69 & 2,70 & 2,68 & 2,77 \\
\hline PT & 1,50 & 2,03 & 1,93 & 2,19 & 3,62 & 3,60 & 3,73 \\
\hline PSOL & - & - & - & - & - & $\mid, 61$ & 1,73 \\
\hline PCB & 1,92 & - & - & - & - & - & - \\
\hline PSTU & - & 2,09 & - & - & - & - & - \\
\hline PSB & 2,21 & 2,35 & 2,81 & 2,85 & 3,48 & 3,75 & 4,05 \\
\hline PPS & - & 2,94 & 3,03 & 3,76 & 3,86 & 4,85 & 4,67 \\
\hline PDT & 3,12 & 3,51 & 3,26 & 3,43 & 4,07 & 4,09 & 4,22 \\
\hline PSDB & 3,95 & 4,37 & 5,86 & 6,09 & 5,91 & 5,83 & 6,04 \\
\hline PV & - & - & - & - & - & 4,59 & 4,63 \\
\hline PMDB & 4,89 & 5,03 & 5,48 & 5,97 & 5,83 & 5,85 & 6,08 \\
\hline PP & - & 6,30 & - & - & - & - & - \\
\hline PSD & - & - & - & - & - & - & 6,58 \\
\hline PR & - & - & - & - & - & 6,89 & 6,91 \\
\hline РТВ & 6,92 & 6,75 & 7,28 & 7,12 & 6,70 & 6,57 & 6,45 \\
\hline$P L$ & 7,24 & 7,36 & 7,48 & 7,05 & 6,88 & - & - \\
\hline PRN & 7,43 & 8,32 & - & - & - & - & - \\
\hline PDC & 7,43 & - & - & - & - & - & - \\
\hline PFL & 7,74 & 7,51 & 8,10 & 8,21 & 7,77 & - & - \\
\hline PPR & - & 7,75 & - & - & - & - & - \\
\hline DEM & - & - & - & - & - & 7,89 & 8,07 \\
\hline PP_PPB & - & - & 8,38 & 8,57 & 7,78 & 7,72 & 7,46 \\
\hline PDS & 8,47 & - & - & - & - & - & - \\
\hline
\end{tabular}

Fonte: Power e Zucco Jr. (201I)

A Figura 2 mostra a evolução dos votos com os partidos classificados nestas grandes famílias. $\mathrm{O}$ que se vê é uma relativa continuidade, muito próxima àquela vislumbrada no sistema europeu. Esquerda e direita começam e terminam com fatias de votos muito próximas. Se, em 1990, alguém apostasse que, nos próximos 25 anos a esquerda teria os mesmos 
$30 \%$ dos votos que obteve naquela eleição erraria apenas duas vezes por mais de 5\%. Há um aumento da participação da esquerda no total de votos nas eleições de 2002, casada com a chegada do Partido dos trabalhadores (PT) à presidência. Estes votos vêm basicamente do centro já que a direita não perde votos nestas eleiçóes. Isto está de acordo com outros trabalhos (LIMONGI; GUARNIERI, 2014, 2015) onde se mostrou que a vitória do PT em 2002 se deu, em grande parte, devido à implosão do PSDB no Nordeste do país. A partir de 2002 a fatia da esquerda volta aos mesmos patamares de antes.

Já a direita, que conseguiu manter sua fatia até as eleições de 2002, perdeu votos a partir de 2006, somente se recuperando nas eleiçóes de 2014. Mais uma vez, a oscilação é muito pequena e se dá mais por troca de votos com partidos do centro do que em trocas com a esquerda. Infelizmente, no momento em que este artigo foi escrito, não se encontravam disponíveis os dados do último survey que cobre as eleiçóes de 2018 quando partidos novos de direita ganharam uma grande fração dos votos à custa dos partidos de centro.

É bom lembrar que o centro é ocupado por partidos diferentes e que a posição ideológica destes partidos muda com o tempo. Em 1990, tínhamos apenas o PMDB no centro. Neste ano, os parlamentares entrevistados por Thimoty Power posicionaram o PSDB à esquerda. Em 1994 e 1998, o PSDB passou a ser considerado um partido de centro. Em 2002, o PSDB passou à direita e deixou o PMDB sozinho novamente no centro, o que pode explicar, junto com o crescimento do PT, a forte contração dos votos nesta família. Em 2006, o PDT se juntou ao PMDB e ao PSDB no centro. Em 2010, PPS e PV também se juntaram à família; e, em 2014, o PSDB passou novamente à direita, acompanhado, pela primeira vez, pelo PMDB. Isso reforça a importância de se observar famílias e não partidos individuais para se avaliar a estabilidade do sistema. 
Figura 2 - Distribuição da fatia de votos de famílias de partidos agrupados conforme a ideologia

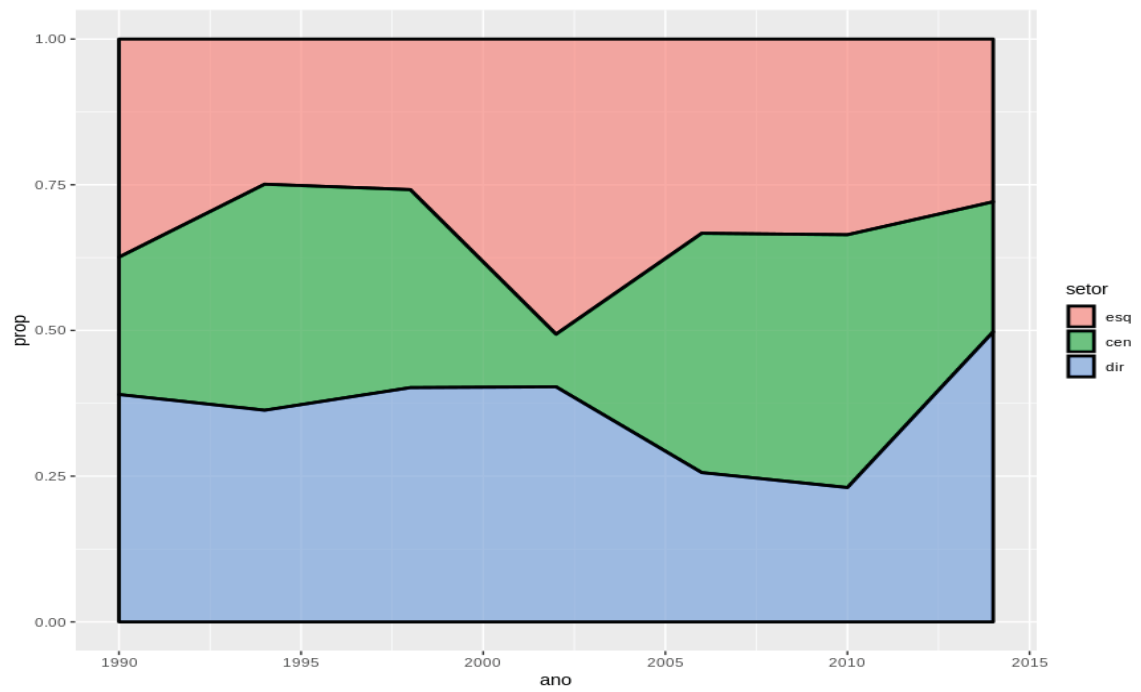

Fonte: Adaptada de Power e Zucco Jr. (2011).

Para termos uma noção mais refinada da dinâmica interpartidária no interior das famílias ideológicas a Figura 3 mostra a evolução de votos de alguns partidos classificados conforme a ideologia. Aqui podemos ter alguma ideia das trocas de votos entre partidos, embora qualquer conclusão nesta direção envolva o risco de cometermos uma falácia ecológica.

A Figura 3 mostra que, desde 1990, houve certa oscilação com o predomínio do centro-direita entre 1990 e 1998, da esquerda, entre 2002 e 2010 e da direita após 2010. É notável o aumento da parte de votos que foi para "outros partidos de esquerda" em 2006 e para "outros partidos de direita" a partir de 2010. Se o primeiro movimento pareceu atingir mais o PT, o segundo tirou votos do centro (PMDB e PSDB). O PT, que dividia a esquerda com o PDT em 1990, passou a dominar esse campo a partir de 1998, mas perdeu essa hegemonia em 2006 com a entrada de partidos como o PSOL. Já o DEM/PFL e o PP/PDS, que dominavam a direita, enfraqueceram com o tempo. $\mathrm{O}$ aumento dos votos da direita efetivou-se 
todo a partir de partidos pequenos como o PRB e o PSL. No entanto, esse crescimento não ocorreu com a retirada de votos da esquerda, mas sim com votos advindo de partidos de centro-direita como o PMDB e PSDB.

Figura 3 - Distribuição da fatia de votos de partidos selecionado classificados conforme a ideologia

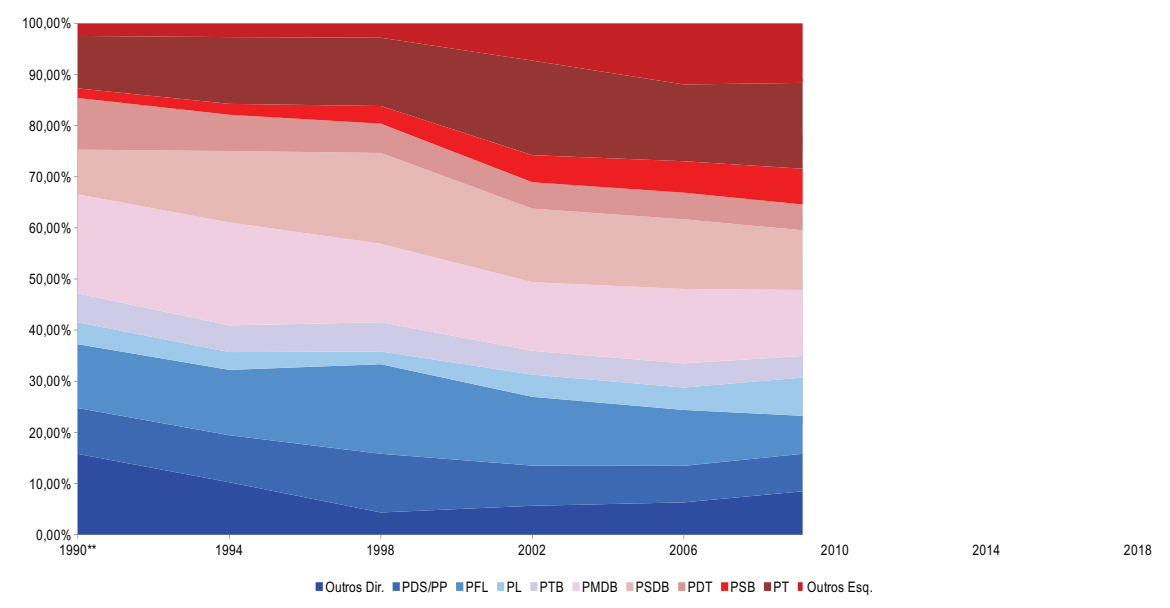

Fonte: Adaptada de Tribunal Superior Eleitoral (anol990 - 2010?).

Embora a classificação em esquerda e direita permita estabelecermos semelhanças ente os partidos, não se tata propriamente de uma clivagem no sentido elaborado por Lipset e Rokkan (1967). Como define Bartolini e Mair (1990) com base em Ray e Taylor (1970) clivagens requerem não apenas estratificação social (de acordo com a classe, religião etc.) e consciência de grupo (de acordo com diferentes valores e/ou preferências) mas também certa organização (na forma de um partido político, sindicato etc.) que ajude o grupo a perceber seus interesses e/ou suas crenças.

Mair e Mudde (1998) sugerem que, além da ideologia, a origem dos partidos também poderia ser utilizada para classificá-los em famílias. Por origem, os autores entendem uma identidade "genética" compartilhada. Partidos que foram mobilizados pelos mesmos movimentos ou que estavam no mesmo lado de uma clivagem no momento em que surge a democracia de massa (quando há ampliação do sufrágio) são considerados da mesma família. 
O atual sistema partidário brasileiro surge com a abertura democrática entre o final dos anos 1970 e começo dos 1980 do século XX. As principais clivagens que levarão à estruturação do sistema estavam ligadas ao modo como as elites políticas se posicionaram diante da transição. Conforme Przeworski (1991), a transição para a democracia no Brasil teria se efetivado por uma emancipação pactuada, isto é, por negociações ente as forças da ditadura e as forças democráticas. Neste tipo de transição, despontariam quatro atores políticos: os "linha-dura" e os "reformistas", no interior do bloco autoritário, e os "moderados" e os "radicais", na oposição (O’DONNELL, 1982).

A eleição indireta de Tancredo Neves para presidente, em 1984, permite identificarmos esses quatro atores na transição brasileira. Tancredo era o candidato de uma aliança entre os reformistas e os moderados. Os primeiros estavam representados no Partido da Frente Liberal, o PFL. Os moderados faziam parte do PMDB principal partido de oposição ao regime militar. Tancredo tinha como adversário Paulo Maluf do PDS. Maluf teve sua carreira política associada ao presidente Costa e Silva, líder dos linha-dura. A candidatura de Maluf ocorreu contra a vontade dos militares reformistas. Estes preferiam o nome do coronel na reserva do exército e ex-ministro Mario Andreazza, mas foram derrotados na convenção do partido. Essa derrota fez com que várias lideranças políticas do PDS, ligadas aos reformistas, abandonassem o PDS e fundassem o PFL.

Antes da eleição indireta de Tancredo, partidos de esquerda o PT e o PDT, junto com o PMDB, buscaram mobilizar a população para pressionar pela aprovação da emenda do deputado Dante de Oliveira (PDT) para que as eleiçôes de 1984 fossem diretas. Apesar de levar multidóes às ruas, a emenda foi derrotada. Com a derrota, o PMDB encampou a candidatura de Tancredo Neves. O PT se recusou a apoiar esta candidatura e o PDT rompeu com o governo assim que o vice-presidente José Sarney, que vinha do PFL, assumiu o governo após a morte de Tancredo.

Assim temos os quatro atores que aparecem no momento de transição para a democracia e que se distinguem por um maior ou menor apoio ao pacto de emancipação. De um lado, temos os linha-dura, agrupados no PDS, e os reformistas, representados pelo PFL; de outro, temos os 
moderados, representados pelo PMDB e os radicais, onde se encontram o PT e o PDT.

Havia uma quinta força, agrupada no PTB, que não se combina facilmente com nenhum dos quatro atores, mas que vai ser uma força constante em todo período. Esse partido surgiu sob o patrocínio do governo militar com o intuito de impedir que Leonel Brizola, que viria a se tornar presidente do PDT e que era uma das principais lideranças da esquerda, refundasse a sigla que comandava o país na época do golpe de 1964 (BENEVIDES, 1989). Atuava como braço auxiliar do PDS em troca de posiçôes no governo. Esse tipo de atuação do partido, de caráter instrumental, foi constante em todo período pós-democratização com outros partidos sendo formados com o intuito de tentar enfraquecer e dividir a oposiçáo.

Novos partidos surgiram por conta de cisóes no interior daqueles que apareceram no momento da transição e por fusôes e incorporaçôes em momentos posteriores. Nesse sentido, temos verdadeiras famílias com ancestrais, descendentes e matrimônios. O PSDB, por exemplo, é "filho" do PMDB e tem como irmãos o PC do B, o PPS, o PCB e o PPL, embora estes irmão em nada se pareçam. De uma cisão do PTB surgiu o PT do B que resolveu mudar seu nome para AVANTE. O PL, cria do PFL, e o PRONA se "casaram" e formaram o PR que adotou os pequenos PGT e $\mathrm{PTN}^{5}$. E temos, também, o PDS que, em vários casamentos, se transformou em PPR, PPB e, por fim, em PP.

Existem também partidos que surgem de fora do sistema. Partidos genuinamente novos. São partidos que nascem de novas clivagens de caráter ideológico, como o Partido Verde, o PHS e o PSB ou religioso, como o PDC, PSC e o PATRI. Estes formarão uma sexta família, embora seus membros tenham em comum apenas a origem externa e um forte componente ideológico.

A partir destas seis forças, podemos tentar agrupar os partidos atuais conforme sua vinculação genética a um destes atores. O Quadro 1 mostra as seis famílias e os partidos que as comporiam ${ }^{6}$.

\footnotetext{
5 Os partidos brasileiros, quando surgem, costumam adotar siglas que já existiam. Temos assim vários PSDs na história brasileira, assim como PTNs e PPs etc.

6 Toda classificação imbute algo de arbitrário e demanda alguma justificativa. Na classificação pela origem, pode causar estranheza a classificação do PCdoB e do PCB na família originada pelo PMDB. Justifico essa classificação
} 


\section{Quadro I - Famílias de partidos conforme sua origem}

\begin{tabular}{|l|l|}
\hline Linha-dura & PP/PPB/PPR/PDS, PRP, PRTB \\
\hline Reformistas & PFL, PR/PL/PGT/PTN, PRB, PSD \\
\hline Moderados & PMDB, PCdoB, PPS, PSDB, PCB, PPL \\
\hline Radicais & PT, PDT, PSTU, PCO, PSOL \\
\hline Instrumentais & $\begin{array}{l}\text { PTB, AVANTE/PTdoB, PTN, PROS, PTC/PRN/PJ, PMB, } \\
\text { SOLIDARIEDADE }\end{array}$ \\
\hline Novos & PSB, PSC, PMN, PV, PHS, PDC, PSL, PATRI/PEN, NOVO, REDE \\
\hline
\end{tabular}

Fonte: Adaptada de Tribunal Superior Eleitoral (https://www.tse.jus.br/partidos/partidos-politicos/ historico) e de Dicionário Histórico Biográfico Brasileiro (DHBB) do CPDOC-FGV (https://cpdoc.fgu.br/acervo/dhbb?).

A Figura 3 mostra a evolução da proporção de votos de cada família. Vemos que, na eleição de 1986, reformistas e moderados dominaram a arena eleitoral, como seria esperado visto que são essas forças que comandaram a transição para a democracia. Como vimos PFL e PMDB se juntaram na candidatura Tancredo Neves e ganharam a presidência. Após a morte de Tancredo, José Sarney assumiu o governo e, às vésperas das eleições de 1986, fez um pacote econômico, o "Plano Cruzado", que conseguiu, por um curto período de tempo, mas o suficiente para cobrir o período eleitoral, brecar a escalada da inflação. O sucesso deste plano econômico fez com que o PMDB e o PFL elegessem todos os governadores de estado e uma maioria de representantes para a Câmara dos Deputados.

Com o tempo, reformistas e moderados foram perdendo espaço, com algumas oscilaçôes. Embora essas famílias tenham se dividido internamente em vários partidos, sua fatia de votos declinou quando comparamos os dois limites temporais da Figura 4. Mas, esse declínio não foi igual para as duas famílias. Enquanto os reformistas mantiveram e até expandiram um pouco sua fatia de votos nos dois extremos da figura, perdendo poucos

pelo fato de estes partidos, junto com o MR8 que se transforma no PPL, e que somente foram legalizados após 1985, terem atuado politicamente no interior do PMDB. A classificação do PRB na família reformista e não nos novos se deve ao fato de suas lideranças terem atuado majoritariamente no PL que teve sua origem em dissidentes do PFL. O Solidariedade foi classificado como instrumental pelo fato de sua principal liderança, Paulinho da Força, ter atuado no PTB antes de migrar para o PDT. 
votos nas eleiçóes intermediárias, os moderados perderam constantemente sua participação chegando a 2018 com menos da metade da proporção de votos que recebiam na década de 1990. Em 2018, os dois partidos que mais perderam votos e cadeiras foram o PMDB e o PSDB.

Os radicais já recebiam em 1986 uma fatia significativa de votos que mantiveram até o final do período, em 2018, com momentos de expansão como em 2002. Isso se deve, em parte, à hegemonia do PT na família. Os partidos instrumentais seguiram o mesmo padrão, mantendo a mesma fatia de votos em todo o período.

linha-dura pelo voto de partidos novos. Os novos partidos veem sua participação no total de votos aumentar desde 2002. Em 2018, com a maciça votação do PSL, a fatia de votos dos novos partidos ultrapassou os $25 \%$. Isso se deve a um aumento do número de partidos nesta família assim como da quantidade de votos que estes partidos receberam. A imagem invertida do sucesso dos novos partidos é o declínio dos linha-dura que, a partir de 2006, passaram a ter participaçáo ínfima na arena eleitoral.

Com exceção da "troca" entre os linha-dura e novos partidos o sistema aparenta certa estabilidade. Metade das famílias - os reformistas, os radicais e os instrumentais - chegaram a 2018 com praticamente a mesma fatia de votos que tinha em 1986. Toda ação se concentra na entrada de novos partidos e no declínio dos linha-dura. A queda dos moderados foi muito acentuada nas eleiçôes de 2018, mas ainda não podemos afirmar que se estabeleceu um padrão. Esta família sempre teve entre 30\% e 40\% dos votos com exceção das eleiçóes de 1986, 2002 e 2018. Portanto, as eleiçóes de 2022 mostrarão se voltamos a esse padrão ou se o avanço de novos partidos vai passar a atingir os moderados agora que os linha-dura têm uma participação ínfima nos votos. 
Figura 4 - Distribuição da fatia de votos de famílias de partidos agrupados conforme a origem

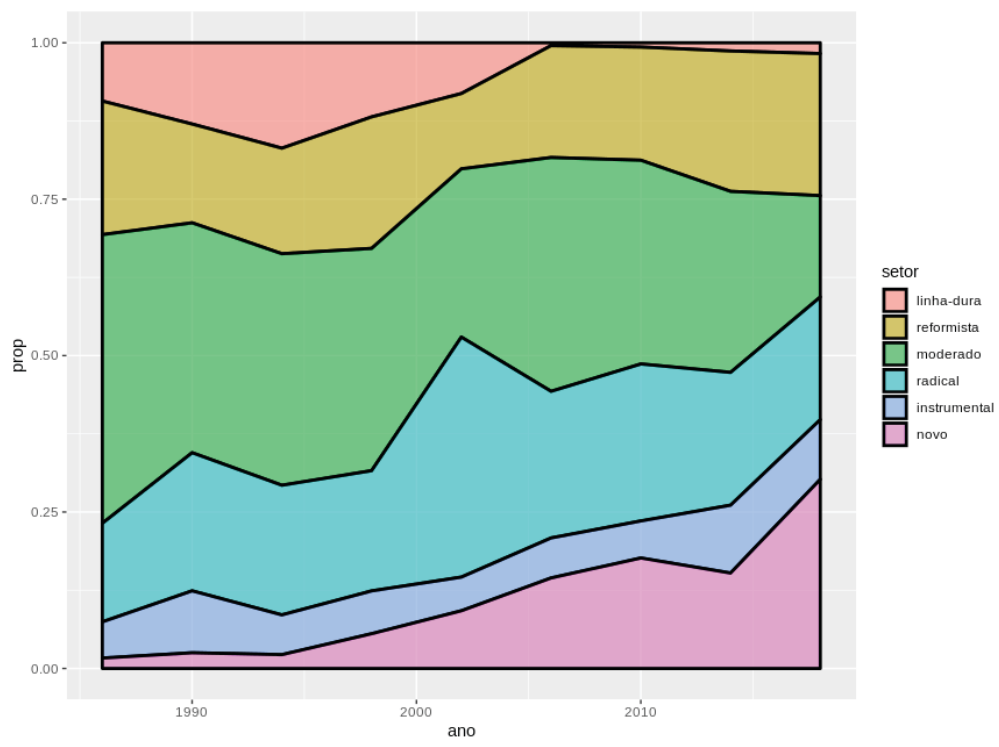

Fonte: Adaptada de Tribunal Superior Eleitoral (1990-20/0).

A Tabela 2 mostra a evolução da volatilidade entre famílias ideológicas e de origem medida pelo índice de Pedersen ${ }^{7}$. Vemos que a média de volatilidade entre famílias é relativamente baixa ${ }^{8}$, tanto para o agrupamento pela origem $(0,13)$ quanto quando agrupamos por ideologia $(0,18)$. As maiores oscilaçóes na família de origem ocorreram em 2002 e 2006, justamente quando começou o crescimento dos novos partidos e houve o declínio dos linha-dura. Os anos de 2002 e 2006, junto a 2014, também apresentaram a maior oscilação entre famílias ideológicas.

7 O uso da volatilidade como indicador de estabilidade do sistema partidário e o modo como ela é operacionalizada são criticadas por autores como Peres (2013) e Bértoa et al. (2017). Embora concorde com essas críticas e as sugestões de aprimoramento faço aqui o uso tradicional do índice de Pedersen ( 1979).

8 A magnitude da volatilidade e sua comparação trazem tantos problemas quanto sua operacionalização (PERES, 2013). Mair, 1993, sugere que, para uma escala que vai de 0 a 100, valores abaixo de 20 são considerados baixos. É neste sentido que observamos que a volatilidade que encontramos é relativamente baixa. Ver também: Braga, 2010. 
Tabela 2 - Índice de Volatilidade de Pedersen entre Famílias de partidos classificados conforme sua origem e ideologia

\begin{tabular}{ccc}
\hline Ano & Origem & Ideologia \\
\hline $\mathbf{1 9 9 0}$ & 0,15 & - \\
$\mathbf{1 9 9 4}$ & 0,05 & 0,15 \\
$\mathbf{1 9 9 8}$ & 0,08 & 0,05 \\
$\mathbf{2 0 0 2}$ & 0,23 & 0,25 \\
$\mathbf{2 0 0 6}$ & 0,23 & 0,32 \\
$\mathbf{2 0 1 0}$ & 0,05 & 0,03 \\
$\mathbf{2 0 1 4}$ & 0,10 & 0,27 \\
$\mathbf{2 0 1 8}$ & 0,16 & - \\
Média & 0,13 & 0,18 \\
\hline
\end{tabular}

Fonte: Adaptada de Tribunal Superior Eleitoral (ano?) e de Power e Zucco Jr. (2011).

Assim, percebemos que, quando pensamos em termos de famílias partidárias, a hipótese do congelamento proposta por Lipset e Rokkan (1967) parece se aplicar tão bem ao Brasil quanto se aplica às democracias europeias apesar de a democracia brasileira ser jovem, o que a levaria a ter maiores oscilaçóes (MAIR, 1997, MAINWARING; ZOCO, 2007). Nosso sistema partidário permite certa previsibilidade em termos programáticos e em termos de genealogia das elites no poder. As eleiçôes de 2018 apresentam um desafio a esta estabilidade das elites com novos partidos substituindo partidos tradicionais, principalmente à direita. No entanto, em linhas ideológicas, a distribuição das forças políticas parece se manter razoavelmente.

\section{Considerações finais}

Neste trabalho, procurei verificar se a hipótese de Lipset e Rokkan (1967) - segundo a qual o sistema partidário europeu havia se congelado - se aplicaria ao caso brasileiro. Embora esta hipótese tenha sido contestada por vários trabalhos empíricos que mostraram a instabilidade do sistema europeu com base em medidas de volatilidade eleitoral como o índice de Pedersen (1979), estes trabalhos cometiam o equívoco de tomar a volatilidade de partidos individuais como um indicador de estabilidade 
de clivagens partidárias (MAIR, 1993, 1997). A hipótese de Lipset e Rokkan propõe a estabilidade das clivagens e não diz nada sobre a votação dos partidos individuais.

Para se verificar a estabilidade das clivagens políticas, é necessário classificar os partidos em famílias que correspondam a estas clivagens. Essa classificação não é algo trivial e uma primeira abordagem sobre o modo de fazê-la foi o trabalho de Mair e Mudde (1998). De fato, quando classificamos os partidos europeus conforme grandes famílias, verificamos que as mudanças foram pequenas, tratando-se mais de oscilaçóes.

No Brasil alguns trabalhos se dedicaram a verificar a estabilidade do sistema partidário olhando para a volatilidade partidária; portanto, para os partidos individualmente (MAINWARING, 1991, 1999; PERES, 2002; BRAGA, 2010). Autores como Peres (2002) e Braga (2010), verificaram a volatilidade ideológica, classificando os partidos em esquerda e direita e Maiwaring, Gervasoni e Espańa-Najera (2016) verificaram a volatilidade extrassistema, classificando os partidos entre os que já estavam no sistema e aqueles que vêm de fora. Apesar disso, não há nenhum trabalho que procure testar a validade da hipótese do congelamento e que siga as recomendaçóes de Mair e Mudde (1998) para se identificar famílias partidárias.

Seguindo Mair e Mudde, propus a classificação dos partidos brasileiros em famílias conforme sua ideologia, aferida legislatura a legislatura pelo Brazil Legislative Survey de Power e Zucco Jr. (2009, 2012), e origem, construída a partir da genealogia dos partidos seguindo a classificação de O'Donnell da posição das elites políticas no momento da transição para a democracia.

Quando classificamos os partidos em famílias, vemos que a hipótese do congelamento se aplica tão bem ao Brasil quanto à Europa. O que temos assistido, aqui como lá, é a substituição das elites partidárias, principalmente à direita, por novas lideranças. Isso impacta, de alguma forma, na volatilidade das famílias por origem; mas, afeta menos a volatilidade entre famílias ideológicas. Essa relativa estabilidade das famílias ideológicas é importante, pois diz respeito ao vínculo programático entre eleitor e representante. Embora o eleitor possa estar buscando novas siglas partidárias, ele faz isso dentro do mesmo espectro ideológico e, à esquerda, entre os partidos "tradicionais". 


\section{Referências}

BARTOLINI, S.; MAIR, P. Identity, Competition, and Electoral Availability: The Stability of European Electorates, 1885-1985. Cambridge; New York; Port Chester: Cambridge University Press, 1990.

BENEVIDES, M. V. O PTB e o trabalhismo: partido e sindicato em São Paulo, 1945-1964. São Paulo: Editora Brasiliense, 1989.

BÉRTOA, Fernando Casal; DEEGAN-KRAUSE, Kevin; HAUGHTON, Tim. The volatility of volatility: Measuring change in party vote shares. Electoral Studies, v. 50, p. 142-156, 2017.

BOlOGNeSI, B. (Org.) A direita no Cone Sul: dinâmicas de poder nos partidos políticos de Argentina, Brasil e Chile. Projeto de pesquisa apresentado à Chamada MCTI/CNPq no 14/2014, jun. 2014.

BRAGA, M. do S. S. Eleiçôes e democracia no Brasil: a caminho de partidos e sistema partidário institucionalizados. Revista Brasileira de Ciência Política, Brasília, n. 4, p. 43-73, jul./dez. 2010 .

CARAMANI, D. The nationalization of politics: the formation of national electorates and party systems in Western Europe. Cambridge: Cambridge University Press, 2004.

CARAMANI, D. Party systems. In: CARAMANI, D. Comparative politics. Oxford: Oxford University Press, 2008. p. 319-347.

CODATO, A.; BOLOGNESI, B.; ROEDER, K. M. A nova direita brasileira: uma análise da dinâmica partidária e eleitoral do campo conservador. In: CRUZ, S. V. e; KEYSEL, A.; CODAS, G. Direita, volver!: o retorno da direita e o ciclo político brasileiro. São Paulo: Editora Fundação Perseu Abramo, 2015. p. 115-143.

DALTON, R. J.; FLANAGAN, S. C.; BECK, P. A. Political forces and partisan change. In: DALTON, R. J.; FLANAGAN, S. C.; BECK, P. A.; ALT, J. E. Electoral change in advanced industrial democracies: Realignment or dealignment. Nova Jersey: Princeton Legacy Library, 1984. p. 451-476.

ELFF, M.; POSTBOX, D. On the distinctiveness of party families. In: Prepared for delivery at the 71th Annual Conference of the Midwest Political Science Association, Palmer House Hilton, Chicago, Illinois. 2013.

ENNSER, Laurenz. The homogeneity of West European party families: The radical right in comparative perspective. Party Politics, v. 18, n. 2, p. 151-171, 2012.

FREIRE, A.; TSATSANIS, E.. Party families, ideological distinctiveness and cohesion: A strong test of the heuristics of the concept of "familles spirituelles". In: ECPR General Conference, Montreal. 2015. 
GOLDER, M. An evolutionary approach to party system stability. Unpublished manuscript. 2003. Disponível em: http://citeseerx.ist.psu.edu/viewdoc/ download?doi=10.1.1.558.4782\&rep=rep1\&type=pdfv. Acesso em: $10 \mathrm{dez} .2018$.

KITSCHELT, H. European party systems: continuity and change. In: JONES, E.; PAUL M. HEYWOOD, P. M.; RHODES, M.; SEDELMEIER, U. Developments in West European Politics. London: Palgrave, 1997. p. 131-150.

KÖNIG, T.; MARBACH, M.; OSNABRÜGGE, M. Estimating party positions across countries and time - A dynamic latent variable model for manifesto data. Political Analysis, v. 21, n. 4, p. $468-491,2013$.

LAMOUNIER, B. Estrutura institucional e governabilidade na década de 1990. In: VELLOSO, J. P. dos R. (Org.). O Brasil e as reformas políticas. Rio de Janeiro: José Olympio, 1992. p. 24-47.

LAMOUNIER, B. A democracia brasileira de 1985 à década de 1990: a síndrome da paralisia hiperativa. In: VELLOSO, J. dos R. Governabilidade, sistema político e violência urbana. Rio de Janeiro: J. Olympio, 1994. págs. 25-64?

LAWSON, K.; MERKL, P. When parties fail. Emerging Alternative. Princeton: Princeton University Press, 1988.

LIMONGI, F.; GUARNIERI, F. Competição partidária e voto nas eleiçóes presidenciais no Brasil. Opiniáo pública, v. 21, n. 1, p. 60-86, 2015.

LIMONGI, F.; GUARNIERI, F. A base e os partidos: as eleiçôes presidenciais no Brasil pósredemocratização. Novos estudos CEBRAP, n. 99, p. 5-24, 2014.

LIPSET, S. M.; ROKKAN, S. Party systems and voter alignments: cross-national perspectives. [Contributors: Robert R. Alford and others]. New York: Free press, 1967.

MAGUIRE, M. Is there still persistence?: electoral change in Western Europe, 1948-1979. In: DAALDER, H.; MAIR, P. (Ed.). Western European Party Systems: Continuity and Change. London: Sage, 1983. p. 67-94

MAINWARING, S. Politicians, parties, and electoral systems: Brazil in comparative perspective. Comparative Politics, v. 24, n. 1, p. 21-43, 1991.

MAINWARING, S. Rethinking party systems in the third wave of democratization: the case of Brazil. Stanford: Stanford University Press, 1999.

MAINWARING, S.; GERVASONI, C.; ESPAÑA-NAJERA, A. Extra-and within-system electoral volatility. Party Politics, v. 23, n. 6, p. 623-635, jan. 2016.

MAINWARING, S.; ZOCO, E. Political sequences and the stabilization of interparty competition: electoral volatility in old and new democracies. Party politics, v. 13, n. 2, p. 155-178, 2007.

MAIR, P. Myths of electoral change and the survival of traditional parties: The 1992 Stein Rokkan Lecture. European Journal of Political Research, v. 24, n. 2, p. 121-133, 1993. 
MAIR, P. Party system change: approaches and interpretations. Oxford: Oxford University Press, 1997.MAIR, P.; MUDDE, C. The party family and its study. Annual review of political science, v. 1, n. 1, p. 211-229, 1998.

O’DONNELL, G. Notas para el estudio de procesos de democratización política a partir del estado burocratico-autoritario. Desarrollo económico, v. 22, n. 86, p. 231-248, 1982.

PEDERSEN, M. N. The dynamics of European party systems: changing patterns of electoral volatility. European Journal of Political Research, v. 7, n. 1, p. 1-26, 1979.

PEDERSEN, M. N. Changing patterns of electoral volatility in European party systems, 19481977: Explorations in explanation. In: DAALDER, H. W.; MAIR, P. (Ed.). Western European party systems: continuity and change, 1983. p. 29-66.

PERES, P. S. Sistema partidário e instabilidade eleitoral no Brasil. In: PINTO, C. R. J.;SANTOS, A. M. (Org.). Partidos no cone sul: novos ângulos de pesquisa. Rio de Janeiro: Fundação Konrad Adenauer, 2002. p. 13-46.

PERES, P. S.. Institucionalização do sistema partidário ou evolução da competição?: uma proposta de interpretaçáo econômica da volatilidade eleitoral. Opinião pública, v. 19, n. 1, p. 21-48, $2013 .$.

PERES, P.; RICCI, P.; RENNÓ, L. R. A variação da volatilidade eleitoral no Brasil: um teste das explicaçóes políticas, econômicas e sociais. Latin American Research Review, v. 46, n. 3, p. 46-68, 2011.

POWELL, E. N.; TUCKER, J. A. Revisiting electoral volatility in post-communist countries: New data, new results and new approaches. British Journal of Political Science, v. 44, n. 1, p. 123-147, 2014 .

POWER, T. J.; ZUCCO JR., C. Estimating ideology of Brazilian legislative parties, 1990-2005: a research communication. Latin American Research Review, Baltimore, v. 44, n. 1, p. 218-246, 2009.

POWER, T. J.; ZUCCO JR., C. Brazilian Legislative Surveys (1990-2013). Harvard Dataverse, V5. 2011. Disponível em: https://hdl.handle.net/1902.1/14970. Acesso em: 10 dez. 2018.

POWER, T. J.; ZUCCO JR., C. Elite preferences in a consolidating democracy: the Brazilian legislative surveys, 1990-2009. Latin American Politics and Society, v. 54, n. 4, p. 1-27, 2012.

PRZEWORSKI, A. PRZEWORSKI. Democracy and the market: Political and economic reforms in Eastern Europe and Latin America. Cambridge: Cambridge University Press, 1991.

ROKKAN, S. Citizens, Elections, Parties: Approaches to the Comparative Study of the Processes of Development, by Stein Rokkan, with Angus Campbell, Per Torsvik, and Henry Valen. New York: McKay, 1970.

ROSE, R; URWIN, D. W. Persistence and change in western party systems since 1945 . Political Studies, v. 18, n. 3, p. 287-319, 1970. 
SEILER, D.-L. Partis et familles politiques. Paris: Presses universitaires de France, 1980.

SINGER, A. Esquerda e Direita no Eleitorado Brasileiro: a identificação ideológica nas Disputas Presidenciais de 1989 e 1994. São Paulo: Edusp, 2002.

TAROUCO, G.; MADEIRA, R. M. Partidos, programas e o debate sobre esquerda e direita no Brasil. Revista de Sociologia e Política, v. 21, n. 45, p. 149-165, mar. 2013.

TRIBUNAL SUPERIOR ELEITORAL (TSE). 2018.

VON BEYME, K. Political parties in Western democracies. Mishawaka: Palgrave Macmillan, 1985.

\section{Stability in change: families of parties and the hypothesis of 'freezing party system' in Brazil (1982-2018)}

\section{Abstract}

In this article I intend to study the dynamics of the Brazilian party system based on the "freezing" hypothesis of the party system of Lipset and Rokkan (1967). When we group the parties into families we see that between the 1990s and the end of the first decade of the 21 st century, the Brazilian party system seems as "frozen" as the European system. After 2010, as in Europe, small right-wing parties gain strength, but the support of the large "left" and "right" families remains relatively constant. I also find some stability when grouping the parties according to their genealogy. This dynamic is similar to that of European party systems. The contribution of the article is to be the first to explicitly test the application of the Lipset and Rokkan's hypothesis of the freezing of the party system to the Brazilian case, as well as the first to suggest the construction of party families in a systematic way using the suggestions of Mair and Mudde (1998).

Keywords: Party system. Volatility. Party families.

Recebido em 09/12/2018

Aprovado em 17/06/2019 